\title{
Analyzing Critical Failures in a Production Process: Is Industrial IoT the Solution?
}

\author{
Shafiq Ahmad $\mathbb{D}$, ${ }^{1}$ Ahmed Badwelan $\mathbb{D D}^{1}{ }^{1}$ Atef M. Ghaleb, ${ }^{1}$ Ammar Qamhan ${ }^{\mathbb{D}}{ }^{1}$ \\ Mohamed Sharaf, ${ }^{1}$ Moath Alatefi $\left(\mathbb{D},{ }^{1}\right.$ and Ammar Moohialdin ${ }^{(D)}{ }^{2}$ \\ ${ }^{1}$ King Saud University, College of Engineering, Department of Industrial Engineering, Riyadh 11421, Saudi Arabia \\ ${ }^{2}$ School of Civil Engineering and Built Environment, Science and Engineering Faculty, Queensland University of Technology, \\ Brisbane 4000, Australia \\ Correspondence should be addressed to Shafiq Ahmad; ashafiq@ksu.edu.sa
}

Received 11 May 2018; Revised 5 August 2018; Accepted 10 October 2018; Published 3 December 2018

Guest Editor: Dongyao Jia

Copyright (C) 2018 Shafiq Ahmad et al. This is an open access article distributed under the Creative Commons Attribution License, which permits unrestricted use, distribution, and reproduction in any medium, provided the original work is properly cited.

Machine failures cause adverse impact on operational efficiency of any manufacturing concern. Identification of such critical failures and examining their associations with other process parameters pose a challenge in a traditional manufacturing environment. This research study focuses on the analysis of critical failures and their associated interaction effects which are affecting the production activities. To improve the fault detection process more accurately and efficiently, a conceptual model towards a smart factory data analytics using cyber physical systems (CPS) and Industrial Internet of Things (IIoTs) is proposed. The research methodology is based on a fact-driven statistical approach. Unlike other published work, this study has investigated the statistical relationships among different critical failures (factors) and their associated causes (cause of failures) which occurred due to material deficiency, production organization, and planning. A real business case is presented and the results which cause significant failure are illustrated. In addition, the proposed smart factory model will enable any manufacturing concern to predict critical failures in a production process and provide a real-time process monitoring. The proposed model will enable creating an intelligent predictive failure control system which can be integrated with production devices to create an ambient intelligence environment and thus will provide a solution for a smart manufacturing process of the future.

\section{Introduction}

Manufacturing companies traditionally are the largest multipliers of economy, employment provider, and GDP contributor. Due to such a critical position in any country's economy, maintaining operational efficiency of a manufacturing concern is crucial. This also results in obtaining higher value products and gaining satisfaction and content of the consumers. Thus, in today's manufacturing environment, maintaining machines and production equipment plays an important role which directly affects the service life of equipment and its production efficiency [1]. The organizational environment is also affected by how a company plans, utilizes and maintains its facilities and manufacturing process in order to enhance its market shares and consumer appreciation [2]. Machine failures are undesirable to any manufacturing company as they result in low production rates and lead to inferior quality. In addition, failures make it difficult for manufacturers to accomplish their commitments to consumers.

It is always vital to maintain production throughput rates and a higher level of product quality. For this reason, an effective failure control system must be implemented to ensure smooth production operations in any company [3]. Process owners should practice a systematic way to study and detect machine failures and their associated causes. The reason is that, in some cases, machine failures can lead to a breakdown situation where machines will be unable to perform any further according to the operational specifications. Some machine failures might be critical to safety and cause very harmful accidents, especially those with hazardous materials. Some failures in manufacturing facilities might be internal as 
discussed above; however; some factors are external which could positively or negatively affect production operations [4]. Factors such as product demand, global warming, and production breakdowns are just a few examples in the present scenario. The more knowledge gained about internal failures as well as the knowledge of external factors will lead to a stable and smooth production operation.

In addition, having knowledge about all (major and minor) failures is considered a valuable input for developing an efficient and effective maintenance program [5]. This is why it is crucial for a manufacturing concern to adopt an effective maintenance strategy to augment production, decrease machine downtime, and consider corrective and preventive maintenance [6]. Subsequently, facility planning facilitates identifying breakdown occurrences and provides and easy access for maintainability of a production process. Facility planning also clarifies what types of repair activities are required. Strategies should be designed and adopted to minimize travelling distances as well as minimize the cost required. This will result in improving the manufacturing processes and reducing their failures in order to achieve the least abruptions in production processes. Raman et al. in their research study argue that facility design depends mainly on the cost of facility construction and the cost of transportation. Further, minimizing the travelling distances can be achieved by better facility layouts which can yield significant impact in reducing machine failures in any manufacturing concern [2].

It is an established fact that study of machine failures and their effect on production processes is popular among scientists and researchers [7]. Maintenance policies and their applications which have significant effect on failure durations are also investigated by many researchers in $[8$, 9]. Problems of testing the homogeneity of critical machine failures such as mean time between failures (MTBF) are also discussed by Pandey and Singh, 2000 [10]. Some studies have discussed how failure analysis could support in building an effective layout model and improve operational efficiency and manufacturing environments [11, 12]. Bröchner highlighted the significance of the relationship between design and facilities management [13], while Jones and Sharp discussed the importance of integrating business strategies in any maintenance program [14]. Most recently, Moohialdin and Hadidi, 2016 [15], discussed the effects of failure types on downtime durations.

The behaviour of machine failures and their associated relations with failure causes using experimental techniques is a well-established research area. Roy and Sutapa, 2004 [16], conducted factorial and fractional factorial experimental techniques to analyze the machine failure data and presented its research outcomes. Another case study is described by Adhikary, 2014 [17], which involves the application of experimental design to reduce machine cycle times in order to eliminate unevenness in the cycle times of two operations. Shen and Wan studied simulation modelling and provided an in-depth evaluation of performance of an existing manufacturing system for a serial production line in a printed circuit board factory. Their simulation analysis is based on full factorial design approach [18]. The most important factors that contribute significantly to operational problems are also studied by Chan and Chan, 2003 [19]. EK used factorial design to conduct experiments where the flow process of boiling and the factors parameters that influence it were studied [20]. Several such studies using experimental design techniques are presented in the literature ([21], (Christen and Soccol, 2000), [22]).

This research study focuses on analysis of machine failure causes. Unlike other research studies presented in the scientific literature which are mainly dedicated to mechanical and electrical failure causes, this study motivates us to investigate the main causes of failures (COF) due to material deficiency and production organizational environment which are adversely affecting the manufacturing processes. To conduct this study, real-time data is collected and analyzed using experimental design methodology and results are presented to help industry practitioners to preclude such critical failures affecting negatively. This case study will also support professionals in controlling machine failures, based on failure prevention strategy rather than failure prediction strategy.

To adapt with the newly introduced smart manufacturing process technologies which are capable of failure prediction rather than prevention strategy, such as Industrial Internet of Things (IIoT) and cyber physical systems (CPS) technologies, we have proposed a conceptual model for detection of critical machine failure more promptly and efficiently. Today's modern era demands a failure prediction strategy and for this purpose, a new approach which can support failure control system with a high level of accuracy and fast delivery is proposed. A smart factory which uses emerging technologies such as IoT and CPS is proposed in this research which will yield significant reduction in failures, enhancing productivity and process efficiency for the entire manufacturing industry [23].

Due to advancement of IoT and other smart sensor technologies, industries are now able to seize the large amounts of data [24] in an industrial process with affordable operational cost. This has motivated industry practitioners to adapt traditional process monitoring functions with IIoT and other smart technologies. This trend is revolutionizing the industrial operations and is also introduced as Industry 4.0. It will help manufacturers to improve production efficiency and product quality [25]. Many researchers have recently contributed to the development of smart manufacturing systems and the data analytics using IIoT based solutions for machine condition monitoring and detection of any failures on real-time bases. For instance, Guo and Qui [26] discussed the new generation of information technology as cloud computing, big data, IoT, and artificial intelligence (AI) and how it became the source of changes in the modern smart manufacturing and production processes. Zhong et al., 2017 [27], also reviewed the Industry 4.0 concept by describing worldwide movements in intelligent manufacturing.

This paper is organized as follows: Section 2 describes the methodology to be used in the study. A description of the conceptual framework of a smart factory is presented in Section 3. Sections 4 and 5 present the data collection and data evaluation, respectively. Section 6 discusses the results. Details of the proposed smart factory model are illustrated in 
Section 7 and finally, the conclusions and recommendations for future research are detailed in Section 8.

\section{Methodology}

Machine failures affect a company's performance. If the machine failures are predominant, then companies will be unable to continue their operations appropriately and will not be able to meet customer demands on time. This research will focus on studying failure patterns and the source cause of these (critical) failures using root-cause analysis. The critical failures (CFs) affect mean-time-between-failure (MTBF) in any manufacturing operation which is a basic measure of a system's reliability and availability. It is defined as the expected elapsed time between two failures of a system which take place throughout normal system operation. It is calculated as an average time between failures of a system. It is normally expressed in units of hours. The higher the MTBF number, the longer the reliability of the system [28]. The failure durations (facility downtime) based on the failure type are also considered in this study. A factorial design model to study behaviour of CFs is developed. Factorial design is a well-established analytical approach, which consists of experimental analysis of two or more failures (factor), each factor with discrete possible values having all possible combinations of these values across all CFs considered. For any process improvement endeavour, factorial design is probably the most powerful experimental and statistical technique for conducting research [20]. Such an experimental technique allows the investigator to study the effect of each factor (failure) on the response variable (i.e., MTBF in this study), as well as the interaction effects that occurred between factors on the response variable.

The experimental methodology is as follows:

(i) Data collection: daily production reports data (secondary) and primary data by conducting several interviews with production staff and maintenance crew are collected for this study.

(ii) Data verification: data verification is undertaken by comparing the production reports data with the machine's time log sheet data.

(iii) Model development: collected data is tested for normality assumption. If the collected data fails to follow normality, an appropriate mathematical transformation technique is used to tackle the issue of nonnormality of the data.

(iv) Checking the model adequacy.

(v) Conducting the experimental analysis using full factorial design approach and investigating which machine failure is dominant (critical) compared to other failures included in the analysis.

(vi) Simultaneous testing: multiple comparisons of results are conducted to determine which means (critical failures) are significantly different among each other.

(vii) Validation: validation of analysis results is conducted by having discussions with industry experts and plant management and results (if needed) are revised afterwards by the stakeholders.

(viii) Future direction: by using smart devices, a smart factory conceptual model is proposed which will help to detect the critical failures more efficiently and promptly.

\section{Conceptual Framework of a Smart System}

A conceptual framework towards a smart manufacturing system is proposed for future. It will comprise three levels which are illustrated in Figure 1.

Level 1: Sensory Devices. Level one will include sensors and cameras which are required for failure detection and data collection as well as alerting if any abnormality occurs during machine functioning and production operations. For instance, thermal cameras and sensors can detect different temperatures; the cameras will alert when any abnormal action occurs.

Level 2: Data Storing and Sharing. A cloud platform will be employed to store large data and therefore allowing for easier access and sharing. The database technology in a cloud platform is used for data storage and analysis. The cloud service system provides data channels for information exchange between the levels. The cloud based systems can provide massive storage resources and low cost computing as well as the flexibility of customizing the operating environment [29]. Thus, data generated by the equipment can be collected and analyzed and messages are sent to the user level. Programmers and developers will be needed to preprogram the optimization unit [30].

Level 3: User Interface. A convenient means of interaction and an appropriate communication platform are required at this level. For a computer network, a software development system can be installed. In order to achieve the required mobile services, we must carry out the development of mobile application software. Therefore, the same system can be flexibly selected and adapted to a mobile terminal. In this process, a terminal device must use $\mathrm{Wi}-\mathrm{Fi}$ or a $3 \mathrm{G} / 4 \mathrm{G}$ signal to connect to the network and access the corresponding Internet cloud service system through the HTTP protocol [31].

Besides many other merits, this proposed system will help in reducing failures and predicting them in advance. This will help to bring down MTBF and to achieve higher productivity and efficiency. Most of the manual work will be replaced by the above-mentioned automated systems, allowing for faster planning as well. Although these systems are cost effective in the long run, initial investment is a bit high. Moreover, the system can be accessed from all networks, making it user friendly anywhere and everywhere.

Limitations. Like any other system, some limitations may be encountered. For example, without motivating and providing any incentives, workers may not be eager to learn and use smart systems correctly and precisely. Machines part failures 

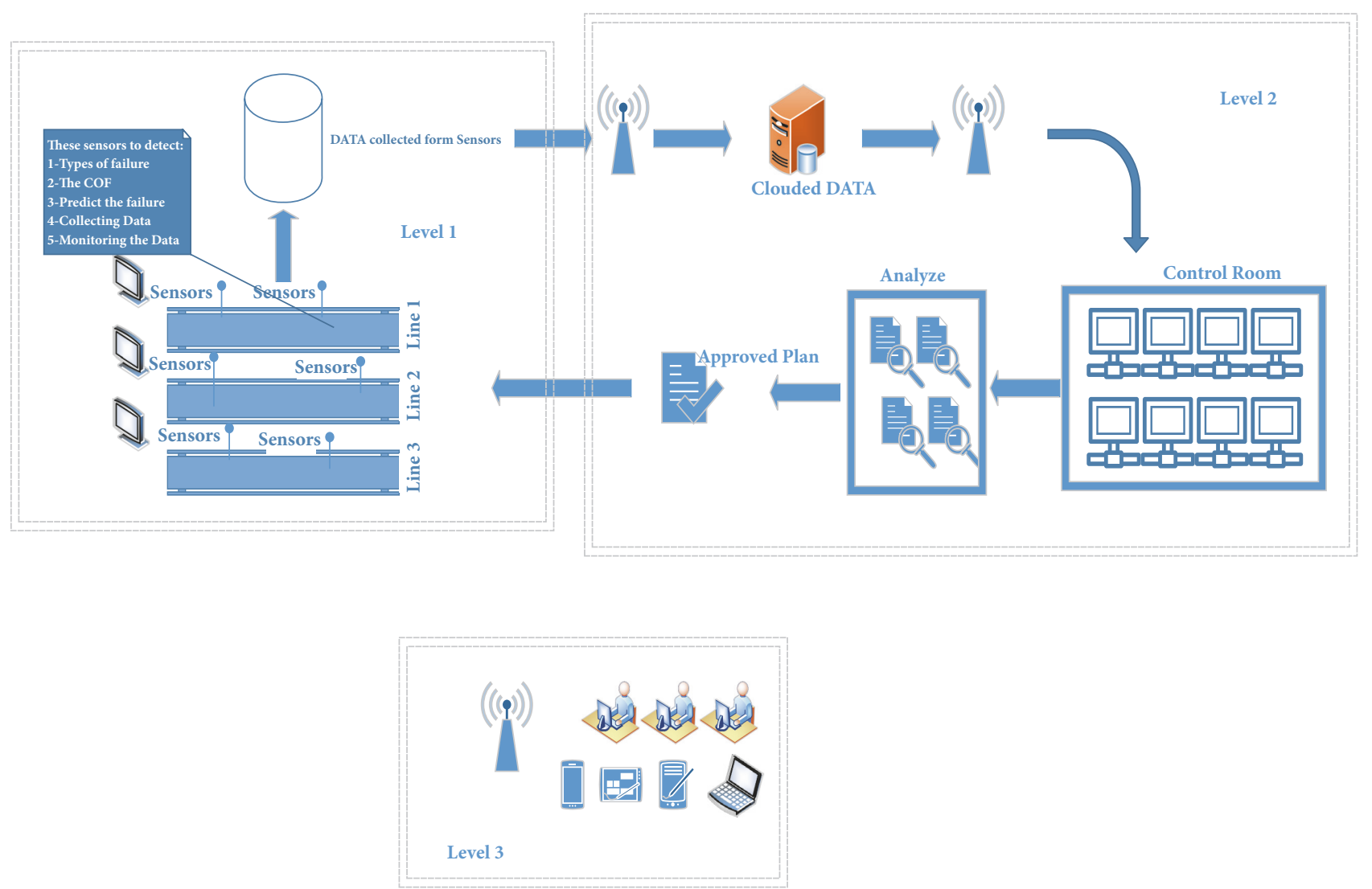

FIGURE 1: Conceptual framework of a smart manufacturing system.

might occurs and need on time replacements; conversely machines might be unable to deliver production targets. Finally, network systems may have outages, which might delay functioning. These limitations should be taken into consideration during system design and implementation.

\section{Data Collection}

A large-scale manufacturing company is selected to conduct this research study. The company produces beverages in several production plants throughout Saudi Arabia with an average annual production capacity of 343,040 metric tons and staff size of 1,400 employees. The company is facing different types of machine failures which cause operational breakdown resulting loss of productivity and throughputs. Machine failures, for instance, mechanical failures, are related to machine components and parts and occurs during machine functioning in the bearings, conveyers, pulleys, rotating shafts, hydraulic and lubricating systems, etc.; electrical failures are related to outage of an electricity supply or a blackout resulting from an electrical breakdown or failure of circuit breakers, etc.; material deficiency failures are related to shortage of raw material or to the material which are available but does not conform to required specification standards; production organization failures are related to any failure in the plant organization which affects production activity such as unavailability of working staff; and planning failures are related to problems which occur due to inadequate planning such as lack of material due to delay in ordering or improper scheduling. A research team was created to approach the facility and collect data about the manufacturing process as well as its failures.

\section{Data Analytic}

The research team reviewed the company's production reports data. The data was collected by conducting interviews involving questions whose answers will support in defining the potential failure areas in the company's equipment and machinery. Facility site visit and taking notes for all observations were also part of the data collection process. Failure types were finally categorized into five factors mentioned earlier: mechanical, electrical, material deficiency, production organization, and planning. Abbreviations used in this study are listed in Table 1.

Hypotheses $\left(\mathrm{H}_{0}, \mathrm{H}_{1}\right)$ were generated to complete this research study. $\mathrm{H}_{0}$ stated that different failures had no significant impact on response, i.e., MTBF, whereas the alternative hypothesis $\left(\mathrm{H}_{1}\right)$ stated that at least one of the failures had a significant impact on MTBF. By applying a significant level of $\alpha=0.05$, the above suggested hypotheses were tested using Minitab version 17.1.0. The model we used included 
TABLE 1: Abbreviations.

\begin{tabular}{lc}
\hline Failure Causes & Abbreviation \\
\hline Mean time Between Failure & MTBF \\
Critical to quality & CTQ \\
Production Type & PT \\
Production Line & PL \\
Cause of Failure & COF \\
Mechanical & Failure 1 \\
Electrical & Failure 2 \\
Material defects & Failure 3 \\
Production organization & Failure 4 \\
Planning defect & Failure 5 \\
Repetition & REP \\
\hline
\end{tabular}

three factors: production type (PT), cause of failure (COF), and production line (PL). The collected data is presented in Table 2.

Data in Table 2, for instance, MTBF (i.e., response), described the time in hours between two failures of the same type. PL, PT, and COF are critical to quality (CTQ) factors. Line 1 and 2 are the production lines in the factory. The products 1,2 , and 3 are different beverage type products. To understand the data with an illustrative example, consider a mechanical failure (Failure 1) is 8.8 hours per week which is recorded as MTBF in line 1 (PL1), Shift 1 for the product 1. Further, factorial analysis is conducted to discover which factors are affecting the production rate significantly. These factors are products (PT), causes of failure (COF), and production line $(\mathrm{PL})$. Furthermore, daily working shift is considered as the blocking factor in this study. As shown in the variable factorial design for model creation, for 3 selected factors with full factorial design (23), 8 runs or more are required. Even though full factorial design requires many runs, it was used to ensure the best results for each factor level and combination. Full factorial design provides complete information unlike to the fractional factorial design which might not provide full information regarding all factors due to the confounding effect.

Model Adequacy Check. To determine whether the model is fitted appropriately to the data; model adequacy test is conducted; residual analysis output plots are presented in Figure 2 which concludes that model adequacy check is successful for further analysis. One can observe that the residuals are distributed normally; residuals versus fits are also randomly scattered; and there is no visible pattern which means that the residuals have a constant variance.

In Figure 2, the histogram of the residuals illustrates that data is slightly positively skewed. However, the residuals versus order of data plot indicates that the residuals are randomly scattered and are equally above and below zero which means that the residuals are uncorrelated with each other. After successfully testing the model adequacy further analysis can be proceeded.

\section{Discussion of Results}

Factorial analysis results are presented in Table 3 . It is customary that if the $\mathrm{p}$-values are greater than $\alpha$ value, which is 0.05 (significance level), then there is no effect on the critical factor and vice versa. In Table 3, for instance, three critical factors (PL, PT, and COF) all have p-value $<0.05$ which is strong evidence that there is a significance effect of these factors at the MTBFs.

Further interactions effects are also studied and presented in Figure 3. The relationship between one categorical factor and a continuous response which is MTBF depends on a second categorical factor value. For instance, considering first column in Figure 3 where product line (PL) represents one categorical variable which has 2 manufacturing lines, 1 and 2 , interaction effects of other 2 categorical variables product type (PT), and causes of failure (COF) with respect to product lines is studied. The relationship between PL and PT in the first column indicates that there is no significant interaction effect; no lines are crossing each other and all are parallel to each other. On the contrary, the relationship between PL and COF in the first column shows a significant interaction effect for Failure 2 (which is electrical failure) with product line 2 (PL2). Similarly, other 2 factors (PT and COF) in the proceeding columns in Figure 3 can be interpreted. It can be easily observed that in the last column the interaction effect is significant between PT and COF, more precisely COF (Failure 2 (electrical)) on product type (PT) 2.

A statistical model is developed as

$$
\begin{aligned}
\mathrm{MTBF}= & 7.053+0.0 \mathrm{PL}(1)+1.808 \mathrm{PL}(2) \\
& +0.0 \mathrm{PT}(1)-0.715 \mathrm{PT}(2)+1.052 \mathrm{PT}(3) \\
& +0.0 \mathrm{COF} \text { (Failure1) } \\
& +4.65 \mathrm{COF} \text { (Failure2) } \\
& +0.78 \mathrm{COF} \text { (Failure3) } \\
& +1.13 \mathrm{COF} \text { (Failure4) } \\
& +1.12 \mathrm{COF} \text { (Failure5) }
\end{aligned}
$$

It represents the relationships and interaction effects between CFs and the COFs and an improved model is presented as

$$
\begin{aligned}
\text { MTBF }= & 7.053+1.808 L_{2}-0.715 P_{2}+1.052 P_{3} \\
& +4.65 F_{2}+0.78 F_{3}+1.13 F_{4}+1.12 F_{5}
\end{aligned}
$$

Note: notations used in (2) are $L_{i}=P L, P_{i}=P T, F_{i}=$ COF(Failure).

In Figure 4, the main effects plot and other interval plots are presented. The main effects plot displays the means for each group within a categorical variable. From the plot, we can see that for all three factors there exists a main effect. For the production line (PL) factor, the MTBF has a higher response in PL2 than PL1. In the PT factor, MTBF response shows a significant difference at PT1, PT2 and PT3; however, the highest response is at PT3. In the third factor, cause of failure (COF), Failure 2, has the greatest main effect since its slope is the highest. 
TABle 2: Experimental data.

\begin{tabular}{|c|c|c|c|c|c|c|c|c|c|c|c|c|c|c|}
\hline Rep & $\mathrm{PL}$ & $\mathrm{PT}$ & $\mathrm{COF}$ & MTBF & Rep & PL & $\mathrm{PT}$ & COF & MTBF & Rep & PL & $\mathrm{PT}$ & $\mathrm{COF}$ & MTBF \\
\hline 1 & 1 & 1 & Failure 1 & 8.8 & 2 & 1 & 1 & Failure 1 & 8.6 & 3 & 1 & 1 & Failure 1 & 7.3 \\
\hline 1 & 1 & 1 & Failure 2 & 9.6 & 2 & 1 & 1 & Failure 2 & 8.0 & 3 & 1 & 1 & Failure 2 & 11.3 \\
\hline 1 & 1 & 1 & Failure 3 & 8.5 & 2 & 1 & 1 & Failure 3 & 10.1 & 3 & 1 & 1 & Failure 3 & 12.7 \\
\hline 1 & 1 & 1 & Failure 4 & 4.3 & 2 & 1 & 1 & Failure 4 & 11.2 & 3 & 1 & 1 & Failure 4 & 8.7 \\
\hline 1 & 1 & 1 & Failure 5 & 7.6 & 2 & 1 & 1 & Failure 5 & 8.1 & 3 & 1 & 1 & Failure 5 & 6.4 \\
\hline 1 & 1 & 2 & Failure 1 & 10.2 & 2 & 1 & 2 & Failure 1 & 7.7 & 3 & 1 & 2 & Failure 1 & 6.6 \\
\hline 1 & 1 & 2 & Failure 2 & 7.8 & 2 & 1 & 2 & Failure 2 & 4.6 & 3 & 1 & 2 & Failure 2 & 6.7 \\
\hline 1 & 1 & 2 & Failure 3 & 7.2 & 2 & 1 & 2 & Failure 3 & 6.3 & 3 & 1 & 2 & Failure 3 & 8.3 \\
\hline 1 & 1 & 2 & Failure 4 & 13.9 & 2 & 1 & 2 & Failure 4 & 14.2 & 3 & 1 & 2 & Failure 4 & 5.6 \\
\hline 1 & 1 & 2 & Failure 5 & 7.6 & 2 & 1 & 2 & Failure 5 & 7.0 & 3 & 1 & 2 & Failure 5 & 8.1 \\
\hline 1 & 1 & 3 & Failure 1 & 7.6 & 2 & 1 & 3 & Failure 1 & 5.6 & 3 & 1 & 3 & Failure 1 & 7.0 \\
\hline 1 & 1 & 3 & Failure 2 & 8.8 & 2 & 1 & 3 & Failure 2 & 8.8 & 3 & 1 & 3 & Failure 2 & 8.0 \\
\hline 1 & 1 & 3 & Failure 3 & 8.1 & 2 & 1 & 3 & Failure 3 & 9.0 & 3 & 1 & 3 & Failure 3 & 12.6 \\
\hline 1 & 1 & 3 & Failure 4 & 9.9 & 2 & 1 & 3 & Failure 4 & 7.7 & 3 & 1 & 3 & Failure 4 & 9.4 \\
\hline 1 & 1 & 3 & Failure 5 & 9.8 & 2 & 1 & 3 & Failure 5 & 14.1 & 3 & 1 & 3 & Failure 5 & 12.4 \\
\hline 1 & 2 & 1 & Failure 1 & 13.2 & 2 & 2 & 1 & Failure 1 & 7.5 & 3 & 2 & 1 & Failure 1 & 8.7 \\
\hline 1 & 2 & 1 & Failure 2 & 15.4 & 2 & 2 & 1 & Failure 2 & 16.0 & 3 & 2 & 1 & Failure 2 & 16.4 \\
\hline 1 & 2 & 1 & Failure 3 & 9.6 & 2 & 2 & 1 & Failure 3 & 5.8 & 3 & 2 & 1 & Failure 3 & 6.8 \\
\hline 1 & 2 & 1 & Failure 4 & 6.5 & 2 & 2 & 1 & Failure 4 & 11.3 & 3 & 2 & 1 & Failure 4 & 8.5 \\
\hline 1 & 2 & 1 & Failure 5 & 9.6 & 2 & 2 & 1 & Failure 5 & 6.9 & 3 & 2 & 1 & Failure 5 & 11.5 \\
\hline 1 & 2 & 2 & Failure 1 & 7.0 & 2 & 2 & 2 & Failure 1 & 6.3 & 3 & 2 & 2 & Failure 1 & 8.3 \\
\hline 1 & 2 & 2 & Failure 2 & 16.1 & 2 & 2 & 2 & Failure 2 & 18.6 & 3 & 2 & 2 & Failure 2 & 11.4 \\
\hline 1 & 2 & 2 & Failure 3 & 10.4 & 2 & 2 & 2 & Failure 3 & 6.5 & 3 & 2 & 2 & Failure 3 & 4.3 \\
\hline 1 & 2 & 2 & Failure 4 & 7.0 & 2 & 2 & 2 & Failure 4 & 9.0 & 3 & 2 & 2 & Failure 4 & 10.4 \\
\hline 1 & 2 & 2 & Failure 5 & 6.9 & 2 & 2 & 2 & Failure 5 & 10.4 & 3 & 2 & 2 & Failure 5 & 8.9 \\
\hline 1 & 2 & 3 & Failure 1 & 8.4 & 2 & 2 & 3 & Failure 1 & 7.9 & 3 & 2 & 3 & Failure 1 & 8.8 \\
\hline 1 & 2 & 3 & Failure 2 & 23.4 & 2 & 2 & 3 & Failure 2 & 22.1 & 3 & 2 & 3 & Failure 2 & 16.0 \\
\hline 1 & 2 & 3 & Failure 3 & 11.4 & 2 & 2 & 3 & Failure 3 & 13.0 & 3 & 2 & 3 & Failure 3 & 8.7 \\
\hline 1 & 2 & 3 & Failure 4 & 7.4 & 2 & 2 & 3 & Failure 4 & 11.1 & 3 & 2 & 3 & Failure 4 & 9.4 \\
\hline 1 & 2 & 3 & Failure 5 & 11.9 & 2 & 2 & 3 & Failure 5 & 12.2 & 3 & 2 & 3 & Failure 5 & 6.0 \\
\hline
\end{tabular}

TABLE 3: Analysing the significance of critical factors.

\begin{tabular}{|c|c|c|c|c|c|}
\hline Source & DF & Adj SS & Adj MS & F-Value & P-Value \\
\hline Model & 31 & 806.73 & 26.02 & 4.99 & 0.00 \\
\hline Blocks & 2 & 8.6 & 4.30 & 0.82 & 0.44 \\
\hline Linear & 7 & 354.71 & 50.67 & 9.71 & 0.00 \\
\hline PL & 1 & 73.57 & 73.57 & 14.1 & 0.00 \\
\hline PT & 2 & 47.37 & 23.68 & 4.54 & 0.02 \\
\hline $\mathrm{COF}$ & 4 & 233.77 & 58.44 & 11.2 & 0.00 \\
\hline 2-Way Interactions & 14 & 383.83 & 27.42 & 5.25 & 0.00 \\
\hline $\mathrm{PL} * \mathrm{PT}$ & 2 & 6.97 & 3.49 & 0.67 & 0.52 \\
\hline $\mathrm{PL} * \mathrm{COF}$ & 4 & 304.97 & 76.24 & 14.61 & 0.00 \\
\hline $\mathrm{PT} * \mathrm{COF}$ & 8 & 71.88 & 8.99 & 1.72 & 0.11 \\
\hline 3-Way Interactions & 8 & 59.59 & 7.45 & 1.43 & 0.21 \\
\hline $\mathrm{PL} * \mathrm{PT} * \mathrm{COF}$ & 8 & 59.59 & 7.45 & 1.43 & 0.21 \\
\hline Error & 58 & 302.67 & 5.22 & & \\
\hline Total & 89 & 1109.41 & & & \\
\hline
\end{tabular}



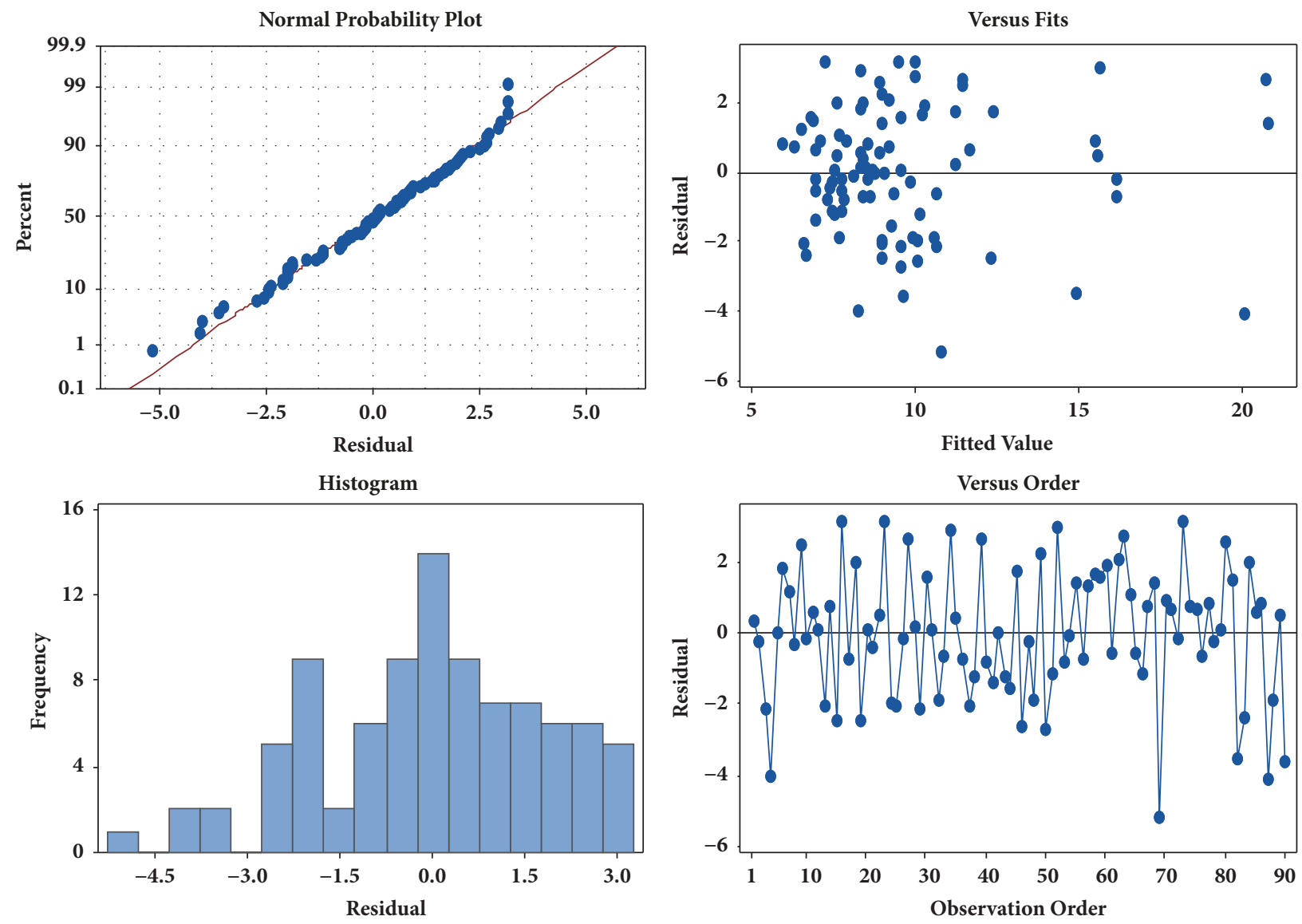

FIGURE 2: Residual plots for testing model adequacy.

Figure 4 also shows interval plots, which is the graphical summary of the distribution of a sample showing its central tendency and variability. As mentioned earlier, Failure 2 has the highest impact on the MTBF.

Figure 5 illustrates Tukey Simultaneous 95\% confidence intervals test, which supports in finding the means of data that are significantly different from each other. If an interval does not contain zero, the corresponding means are significantly different. When a significant difference is found, it indicates that the corresponding response will be significantly affected.

In Figure 5, dotted lines are indicating that Failure 2 is significantly affecting all the other COFs which includes Failure 1, Failure 3, Failure 4, and Failure 5. From the above results and discussions, it can be concluded that electrical failures (Failure 2) are affecting the most to the model factors (PL, PT, and COF). This is reflected using Tukey differences of means test for MTBF.

In the subsequent sections, details of the proposed conceptual model for a smart manufacturing process will be discussed.

\section{Towards a Smart System}

It is a fact that machine failures interrupt production operations causing barricades in meeting consumer demands. So, it is crucial for manufacturing companies to develop and implement an appropriate machine failure control system in order to avoid machine breakdowns and their financial impacts. Since the communication network and sensory technologies are growing rapidly, future manufacturing factories need to embrace them promptly in order to support noninterrupted and smooth production operations. This direction is heading towards inception of fourth industrial revolution called Industry 4.0 [32].

Industry 4.0 era will utilize the Industry Internet of Things (IIoT), which is the interconnection via the Internet of computing devices embedded in everyday objects, enabling them to send and receive data, to create a smart factory environment. The smart factory is the integration of all IoT technological with computer networks, data integration, and analytics to bring clarity to all manufacturing factories [33]. Smart factories have proven to achieve transparency as well as productivity [34]. To implement this smart factory, manufacturing companies use cyber physical systems (CPS) which is a term describing a broad range of complex, multidisciplinary, physically aware next generation engineered system that integrates embedded computing technologies (cyber part) into the physical world [35].

CPSs have great potential for social and economic impact. For example, a CPS-based smart factory can increase energy efficiency of production systems at such factories by 


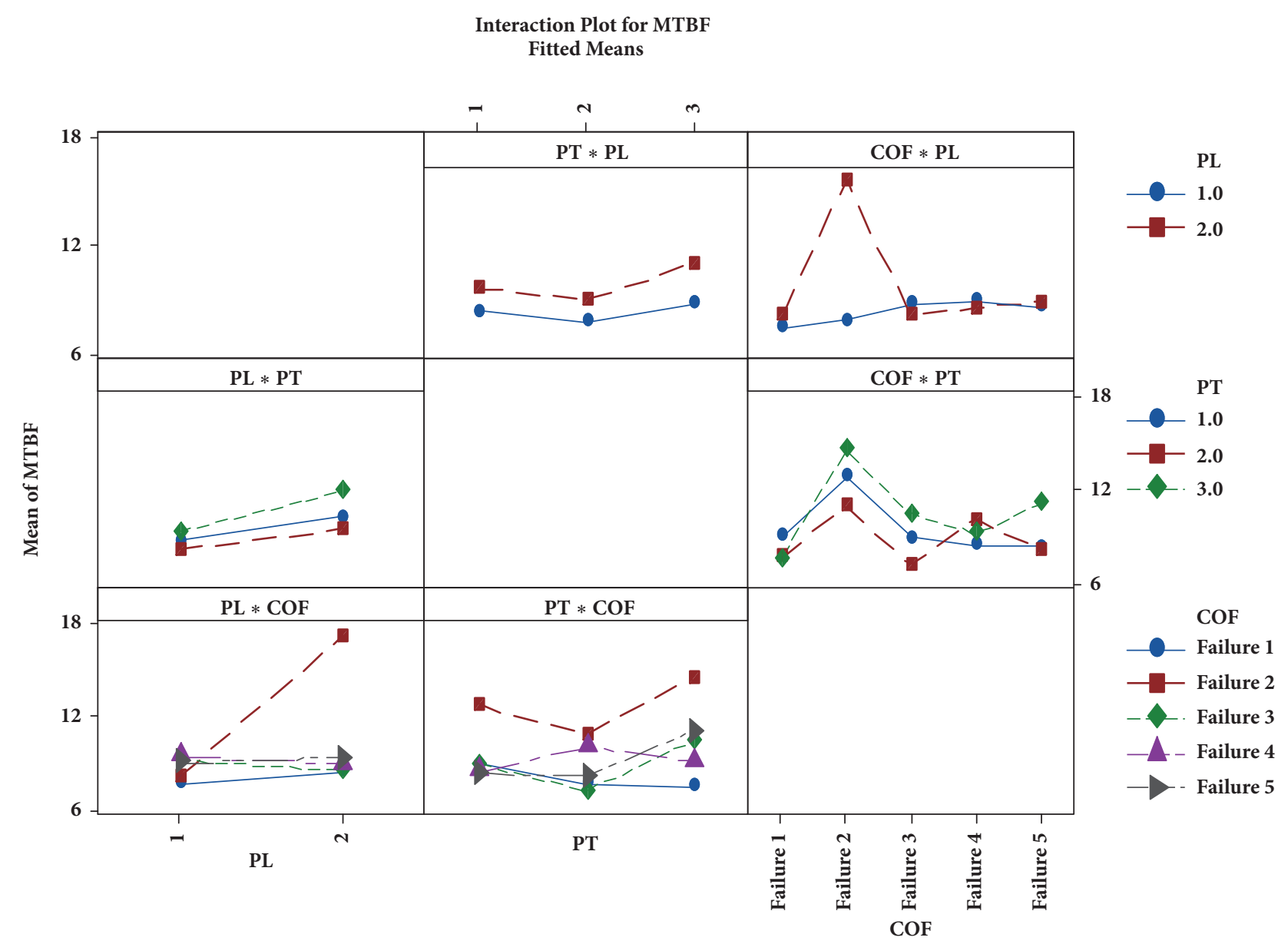

FIGURE 3: Interaction plots.

providing them with decision making at production management level (e.g., production scheduling and maintenance management) [32]. According to a survey by American Society for Quality (ASQ) in 2014, 82\% of organizations which claim to have implemented smart manufacturing systems have experienced increased efficiency, $49 \%$ experienced fewer product defects, and 45\% experienced increased customer satisfaction [36].

7.1. Towards Smart Manufacturing. Monitoring production systems and collecting performance data in real time using smart sensor and communication technologies will have positive impact on maintenance planning and improved production efficiency. For instance, using temperature sensors will allow preemptive actions to be taken when it goes out of range and prevent breakdown. Similarly, preemptive actions can be taken when energy consumption jumped above than normal level for a certain period for time. This will save energy, reduce wastage of defective products, and avoid machine breakdowns. Furthermore, IoT-enabled vision devices will enable machines to predict machine failures and trigger maintenance actions promptly. Thus, the companies which will embrace smart factory concept will benefit high efficiency, less failures due to predictive maintenance strategies $[37,38]$.
In the subsequent sections, a smart factory design using CPS and IoT is discussed.

Some modifications might be required to adapt with the existing manufacturing operations. The proposed smart manufacturing system will consist of the three levels as depicted in Figure 6. Each layer of the system depends on corresponding communication technologies [32] and protocols to communicate with the other layers and coordinate production activities.

\subsubsection{Smart System Structure}

Level 1: Physical Level. This level consists of three different sections which are connected using sensors enabling sensing, communication, and computing (processing; memory) elements in the proposed model. Three levels are discussed as follows.

(A) Materials. Materials which are processed in the manufacturing process are of two types:

(i) Raw Materials. This kind of materials will be used to manufacture the finished products. In this section, the layer is responsible to detect if there is sufficient raw material inventory available to continue operation 


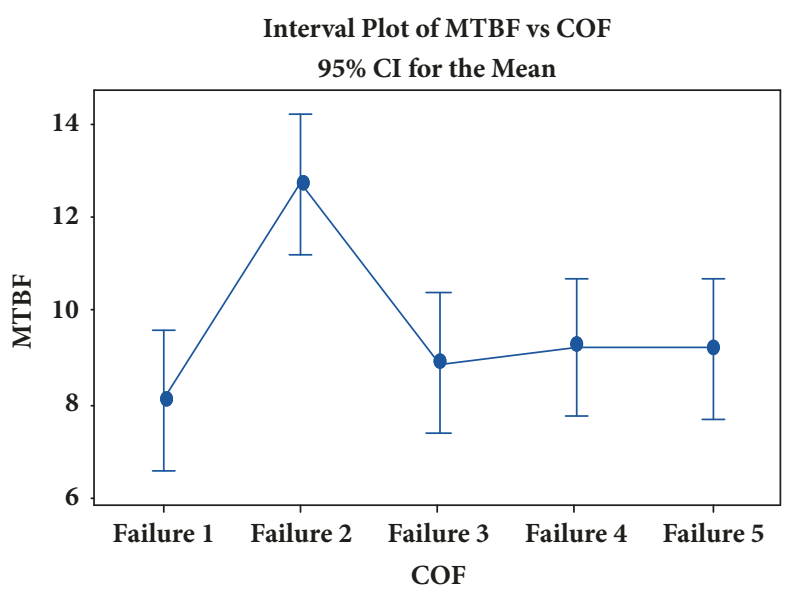

The pooled standard deviation is used to calculate the intervals.

Interval Plot of MTBF vs PT

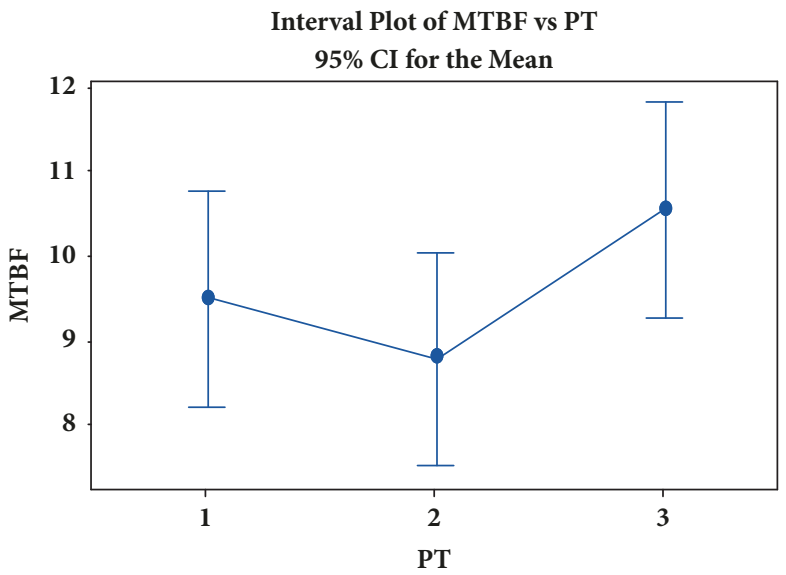

The pooled standard deviation is used to calculate the intervals.

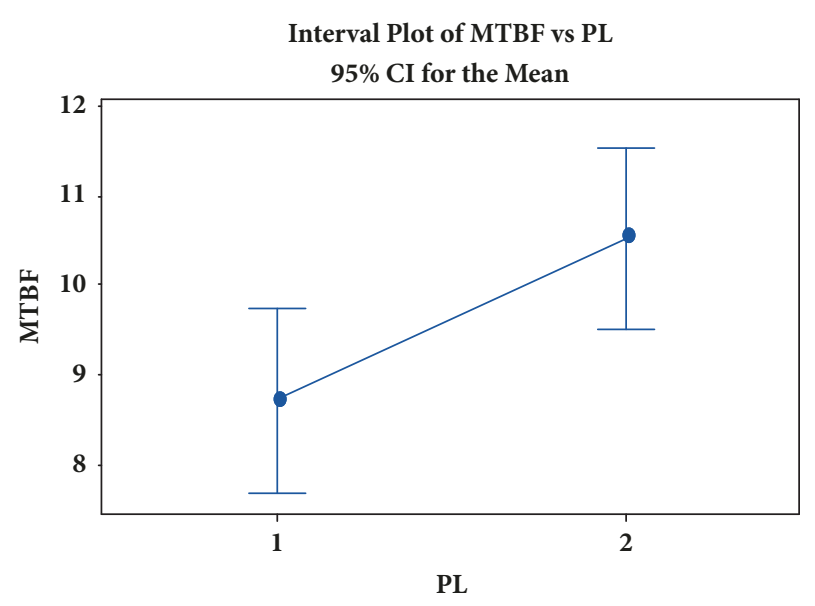

The pooled standard deviation is used to calculate the intervals.

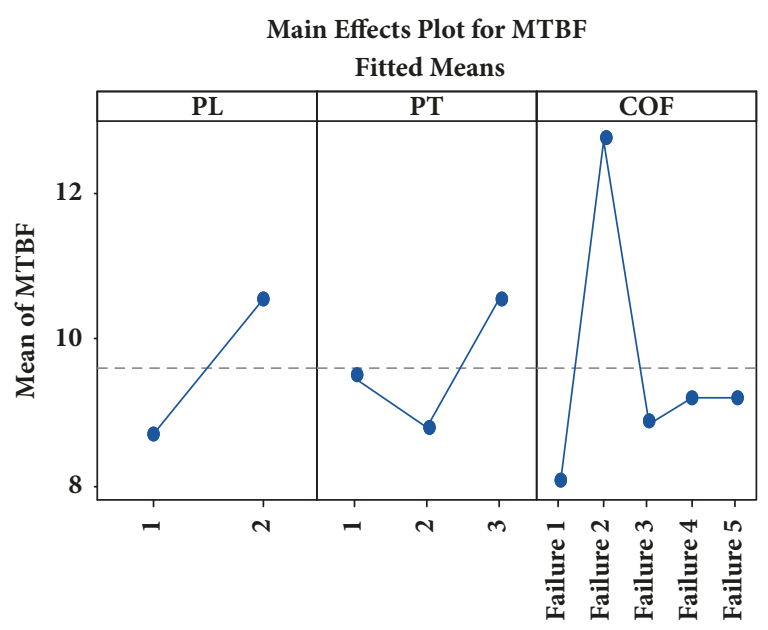

FIGURE 4: Main effects and interval plots.

without facing shortage. For instance, if the raw material analysis report returns to the system with a raw material which is either not qualified to be used or does not comply with required raw material specification requirements needed by manufacturing process, this means material is unfit for use. The software will alert a signal for raw material shortage to avoid any abruptions in the production process.

(ii) Processed Raw Material. The materials which have already met quality requirements and are being processed to eventually produce the new and finished products and ready to be delivered. At this stage, the smart system will detect any issues during material processing, for instance, over or under filled beverage bottles, packaging, etc. The smart system will collect all data of the faults and send it to the control unit.

(B) Robots. Robots are an integral part of any smart system. Robots are designed to carry on various activities in the factory. This section should consider developing ability that a robot can conduct required tasks can acquire the required level of skills and knowledge. In this layer, the control unit analyzes the professional ability and skills of the attending workers and then assigning them to the specific machine based on their skills and production demands. In this way, it can be guaranteed that a machine is being operated by an expert worker and it will help to avoid any planning failures.

(C) Equipment. These are the machines and devices that will be handled by the workers. Through detectors, such as sensors, cameras, and industrial wireless systems, data will be collected and analyzed to alert if there is any instability in the equipment.

Level 2: Control Unit Level. This level is comprised of four units:

(i) Database Unit. This unit collects and categorizes the data received from level 1 . It is the main database for the system, acting as an interface between level 1, level 3 , and the unit itself. All data is stored and sent by IoT devices and can be accessed by the users whenever the data is needed. This unit consists of servers and mirrors to support the data storage in case of any loss of data. It can be accessed through Wi-Fi anywhere and everywhere. 


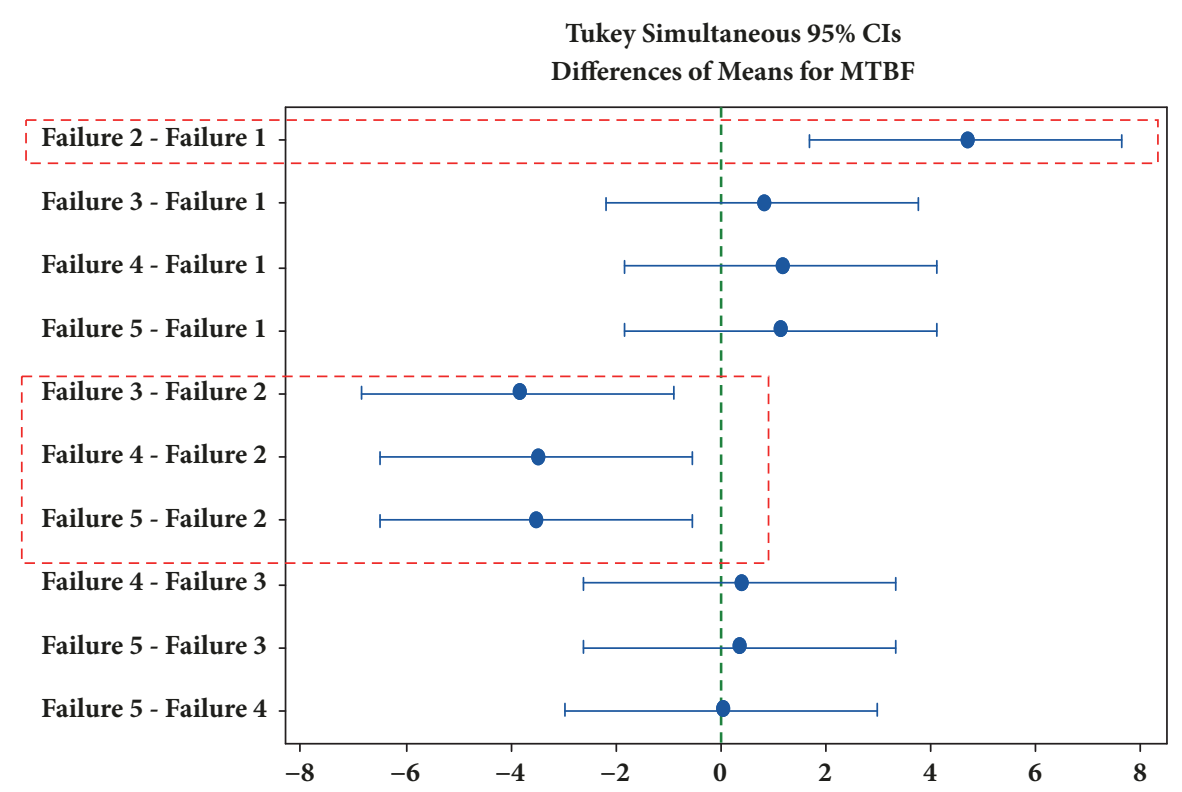

If an interval does not contain zero, the corresponding means are significantly different.

Figure 5: Tukey differences of means test for MTBF.

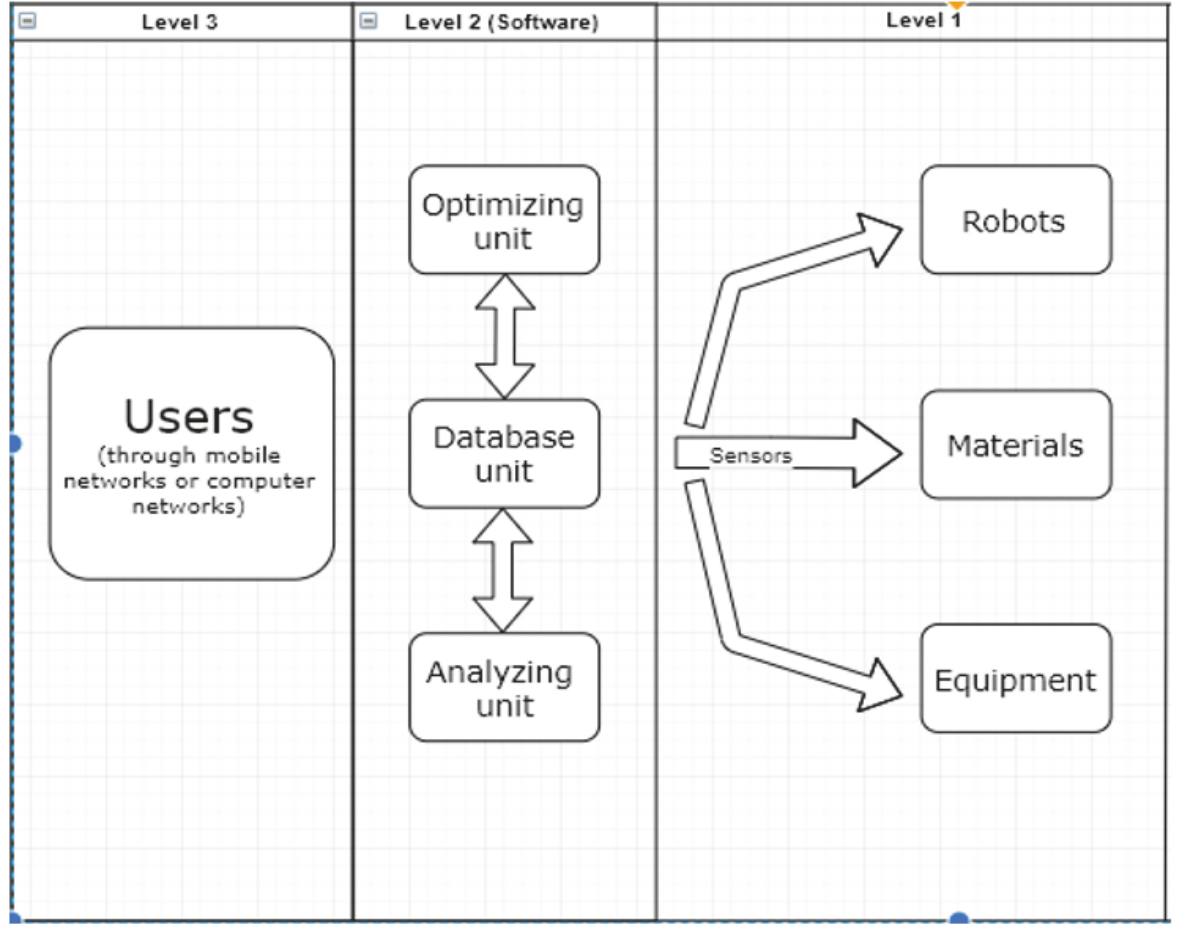

FIGURE 6: IoT based smart manufacturing system.

(ii) Analyzing Unit. This unit analyzes the data in the Database Unit. It reads the data and decides how it should be categorized so that the data can be organized at later stage with its respective category. This categorization facilitates to search the required category data whenever needed. (iii) Optimization Unit. This unit is preprogrammed to carry out the decision-making process. Its job is to data sorting with its respective category.

(iv) Software Unit. Using software, this unit connects the database unit, analyzing unit and optimization unit so 
they can work together to carry out all of the abovementioned actions.

Level 3: User Level. This level will be used for accessing and planning by all users through mobile networks or computer networks. This layer is utilized to provide a personalized customization service and dynamic production process monitoring capabilities to users. In order to achieve effective service, this layer must be user-friendly and have reliable interaction methods.

\section{Conclusion and Recommendations}

In any manufacturing concern, machine failures can occur due to several reasons. This research study has investigated and identified the critical failures and their associated causes which adversely affect the manufacturing process. Realtime machine failure data (secondary data) from production reports and employee interviews (primary) data is collected. Statistical analysis using experimental design technique is performed and the results also demonstrate that the electrical failures (Failure 2) are the most occurring problem among all critical failure causes studied in this research. Production line failure is the one which has also significant effect on the machine failure. However, the product type failure does not contribute to the machine failure. The relationship between production line and production type indicates that there is no significant interaction effect. On the contrary, the relationship between production line and the cause of failures indicates a significant interaction effect, especially for the electrical failure with production line 2. This research study concludes that manufacturing concerns should focus on preventing critical failure and elimination of cause of failures and develop an active predictive failure control system rather than prevention system.

In future research, an effective and efficient failure control system is proposed which is based on smart manufacturing factory and will be comprised of smart sensor and communications technologies. Detailed description of the conceptual model is illustrated in this study for future development and implementation purposes.

\section{Data Availability}

The data used to support the findings of this study are available from the co-author Ammar Moohialdin (ammar.imse@gmail.com) upon request.

\section{Conflicts of Interest}

The authors declare that they have no conflicts of interest.

\section{Acknowledgments}

The authors extend their appreciation to the Deanship of Scientific Research at King Saud University for funding this work through research group no. (RG-1438-089).

\section{References}

[1] J. Wan, S. Tang, D. Li et al., "A manufacturing big data solution for active preventive maintenance," IEEE Transactions on Industrial Informatics, 2017.

[2] D. Raman, S. V. Nagalingam, and G. C. I. Lin, "Towards measuring the effectiveness of a facilities layout," Robotics and Computer-Integrated Manufacturing, vol. 25, no. 1, pp. 191-203, 2009.

[3] C. Shekhar, M. Jain, J. Iqbal, and A. A. Raina, "Threshold control policy for maintainability of manufacturing system with unreliable workstations," Arabian Journal for Science and Engineering, vol. 42, no. 11, pp. 4833-4851, 2017.

[4] M. Fernández-Olmos and M. Ramírez-Alesón, "How internal and external factors influence the dynamics of SME technology collaboration networks over time," Technovation, vol. 64-65, pp. 16-27, 2017.

[5] K. L. Carper, "Failure information: Dissemination strategies," Journal of Performance of Constructed Facilities, vol. 1, no. 1, pp. 1-10, 1987.

[6] J. Moubray, "21st century maintenance organization part I: the asset management model," Maintenance Technology, vol. 16, no. 2, pp. 25-32, 2003.

[7] H. Groenevelt, L. Pintelon, and A. Seidmann, "Production lot sizing with machine breakdowns," Management Science, vol. 38, no. 1, pp. 104-123, 1992.

[8] L. Swanson, "Linking maintenance strategies to performance," International Journal of Production Economics, vol. 70, no. 3, pp. 237-244, 2001.

[9] I. P. S. Ahuja and J. S. Khamba, "Total productive maintenance: literature review and directions," International Journal of Quality \& Reliability Management, vol. 25, no. 7, pp. 709-756, 2008.

[10] A. Pandey and A. K. Singh, "A Bayes test of homogeneity of several means for one parameter exponential populations," Applied Mathematics and Computation, vol. 108, no. 1, pp. 2332, 2000.

[11] B. A. Peters and T. Yang, "Integrated facility layout and material handling system design in semiconductor fabrication facilities," IEEE Transactions on Semiconductor Manufacturing, vol. 10, no. 3, pp. 360-369, 1997.

[12] B. Moua and J. S. Russell, "Evolution of formal maintainability program for large manufacturing company," Journal of Performance of Constructed Facilities, vol. 15, no. 2, pp. 46-53, 2001.

[13] J. Bröchner, "Integrated development of facilities design and services," Journal of Performance of Constructed Facilities, vol. 17, no. 1, pp. 19-23, 2003.

[14] K. Jones and M. Sharp, "A new performance-based process model for built asset maintenance," Facilities, vol. 25, no. 13-14, pp. 525-535, 2007.

[15] A. S. Moohialdin and L. A. Hadidi, "Effect of failure type on downtime duration for a manufacturing facility," Journal of Performance of Constructed Facilities, vol. 31, no. 3, article 04016114, 2016.

[16] S. K. Roy and I. N. Sutapa, "CASE studies of use of design of experiments in material research," Jurnal Teknik Industri, vol. 5, no. 1, pp. 32-40, 2004.

[17] S. N. Adhikary, "A case study in increasing productivity by DOE in manufacturing sector," International journal of Advancement in Engineering Technology, Management and Applide Science, vol. 1, no. 7, 2014. 
[18] H. Shen and H. Wan, "Controlled sequential factorial design for simulation factor screening," European Journal of Operational Research, vol. 198, no. 2, pp. 511-519, 2009.

[19] F. Chan and H. Chan, "Simulation analysis of a PCB factory using factorial design-a case study," The International Journal of Advanced Manufacturing Technology, vol. 21, no. 7, pp. 523-533, 2003.

[20] L. T. Ek, “Quality improvement using factorial design," Paper presented at the 9th Int Convention on Quality Improvement, 2005.

[21] A. B. Medeiros, A. Pandey, R. J. Freitas, P. Christen, and C. R. Soccol, "Optimization of the production of aroma compounds by Kluyveromycesmarxianus in solid-state fermentation using factorial design and response surface methodology," Biochemical Engineering Journal, vol. 6, no. 1, pp. 33-39, 2000.

[22] N. S. Zulu and A. T. Modi, "A factorial experiment to study the effect of seeding rate and nitrogen side-dressing on yields of two dry bean (Phaseolus vulgaris L.) cultivars," 2011.

[23] S. Haller, S. Karnouskos, and C. Schroth, "The internet of things in an enterprise context," in Proceedings of the Future Internet Symposium, 2008.

[24] P. Jiang, K. Ding, and J. Leng, "Towards a cyber-physical-socialconnected and service-oriented manufacturing paradigm: Social Manufacturing," Manufacturing Letters, vol. 7, pp. 15-21, 2016.

[25] J. Wang and J. Zhang, "Big data analytics for forecasting cycle time in semiconductor wafer fabrication system," International Journal of Production Research, vol. 54, no. 23, pp. 7231-7244, 2016.

[26] L. Guo and J. Qiu, "Optimization technology in cloud manufacturing," The International Journal of Advanced Manufacturing Technology, vol. 97, no. 1-4, pp. 1181-1193, 2018.

[27] R. Y. Zhong, X. Xu, E. Klotz, and S. T. Newman, "Intelligent Manufacturing in the context of industry 4.0: a review," Engineering Journal, vol. 3, no. 5, pp. 616-630, 2017.

[28] J. Lienig and H. Bruemmer, Reliability Analysis, Fundamentals of Electronic Systems Design, Springer International Publishing, 2017.

[29] Z. Shu, J. Wan, D. Zhang, and D. Li, "Cloud-integrated cyberphysical systems for complex industrial applications," Mobile Networks and Applications, vol. 21, no. 5, pp. 865-878, 2016.

[30] J. Wan, M. Yi, D. Li, C. Zhang, S. Wang, and K. Zhou, "Mobile services for customization manufacturing systems: an example of industry 4.0," IEEE Access, vol. 4, pp. 8977-8986, 2016.

[31] J. Wan, S. Tang, Z. Shu et al., "Software-Defined Industrial Internet of Things in the Context of Industry 4.0," IEEE Sensors Journal, vol. 16, no. 20, pp. 7373-7380, 2016.

[32] F. Shrouf, J. Ordieres, and G. Miragliotta, "Smart factories in Industry 4.0: A review of the concept and of energy management approached in production based on the Internet of Things paradigm," in Proceedings of the 2014 IEEE International Conference on Industrial Engineering and Engineering Management, IEEM 2014, pp. 697-701, Malaysia, December 2014.

[33] J. Lee, "Smart Factory Systems," Informatik-Spektrum, vol. 38, no. 3, pp. 230-235, 2015.

[34] J. Lee, H.-A. Kao, and S. Yang, "Service innovation and smart analytics for industry 4.0 and big data environment," Procedia Cirp, vol. 16, pp. 3-8, 2014.

[35] V. Gunes, S. Peter, T. Givargis, and F. Vahid, "A survey on concepts, applications, and challenges in cyber-physical systems," KSII Transactions on Internet and Information Systems, vol. 8, no. 12, pp. 4242-4268, 2014.
[36] K. Braley, "Manufacturing Growth Continues but Economy Still a Challenge, According to ASQ Outlook Survey," 2013, http:// www.prweb.com/releases/2013/12/prweb11430148.htm.

[37] Building Smarter Manufacturing With The Internet of Things (IoT), Lopez Research LLC, 2014.

[38] L. Wang, "Cyber manufacturing: research and applications," in Proceedings of the Tenth International Symposium on Tools and Methods of Competitive Engineering, 2014. 


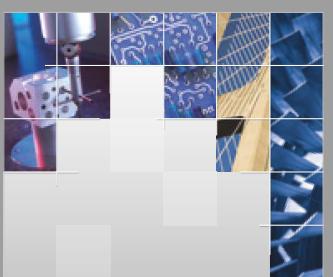

\section{Enfincering}
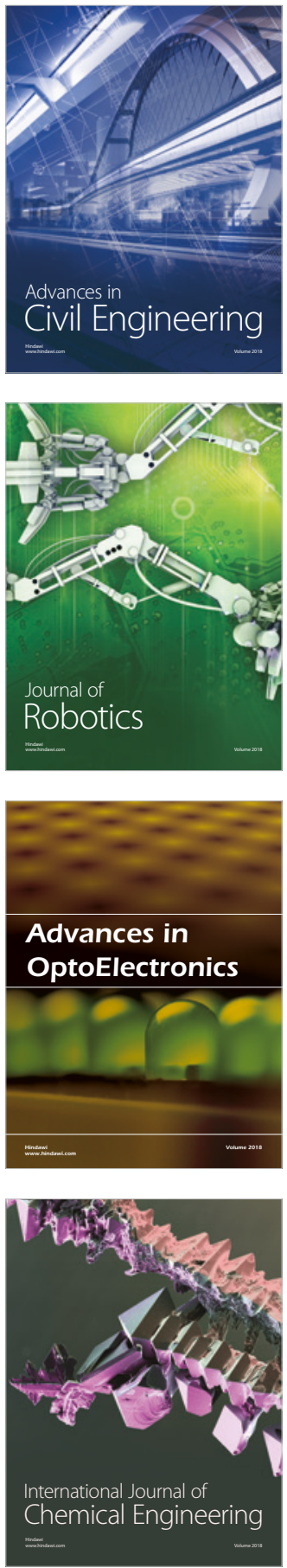

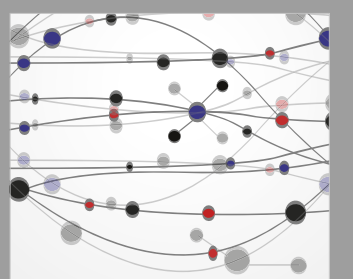

\section{Rotating \\ Machinery}

The Scientific World Journal

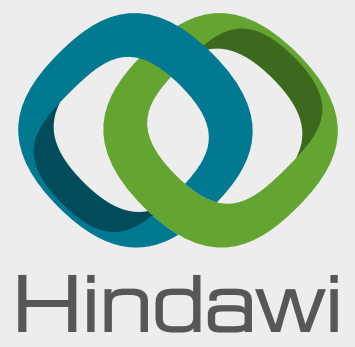

Submit your manuscripts at

www.hindawi.com
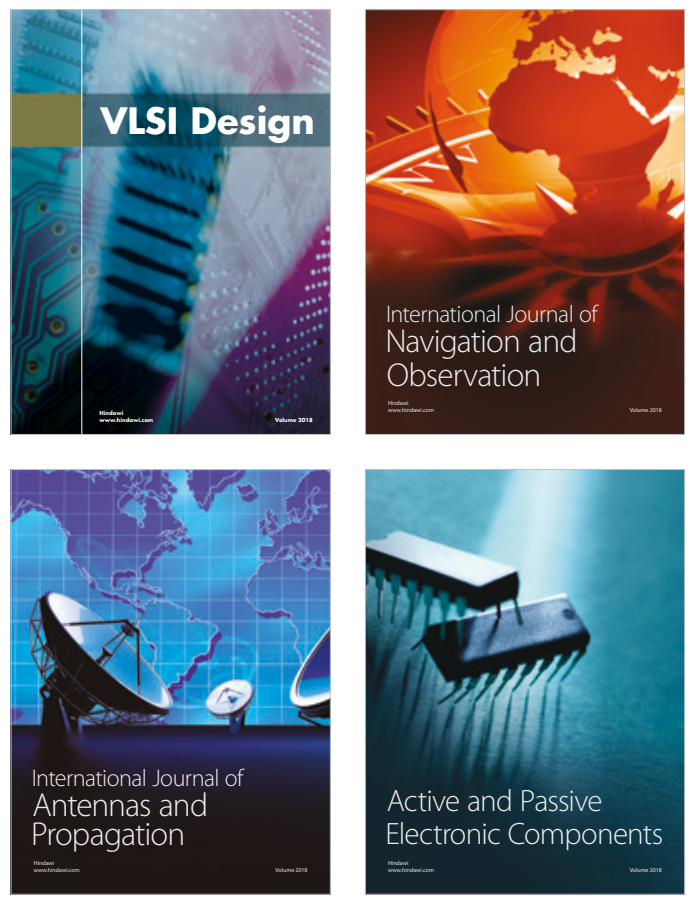
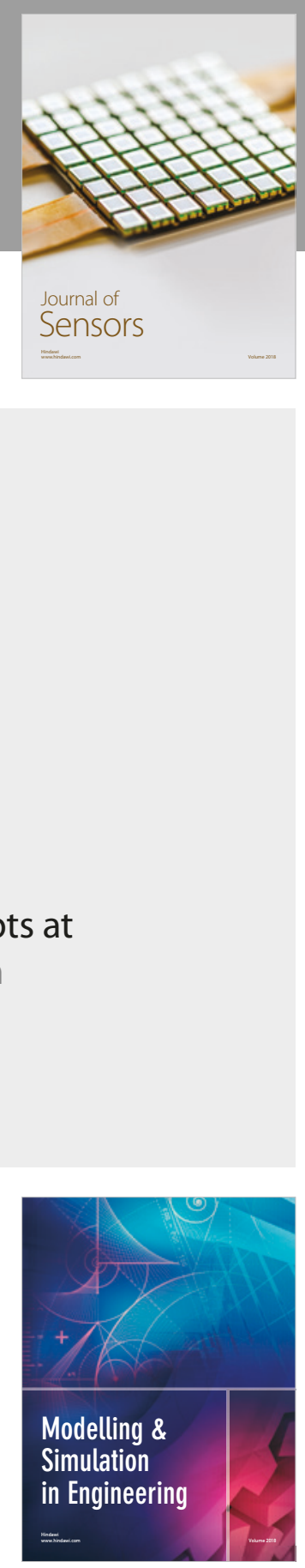

\section{Advances \\ Multimedia}
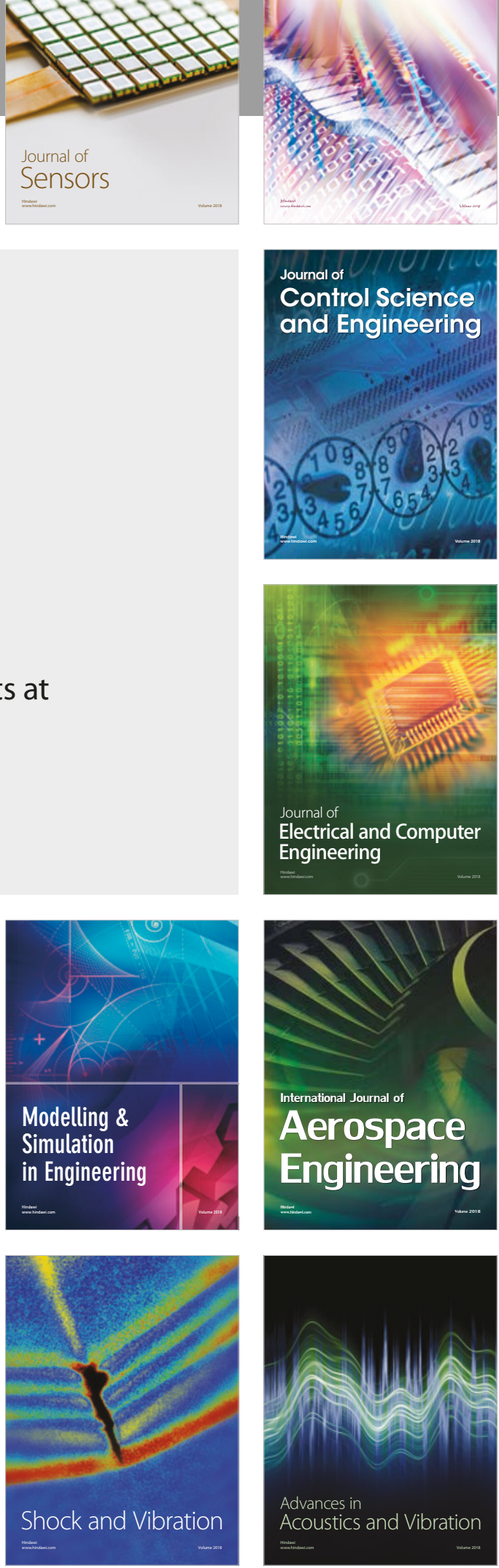